is very small, and their commercial value depends, not upon an examiner's report, but upon the homage paid by all men of science to the path-breaker who opens a new road of research for the benefit of mankind.

Old House, East Street, E. Wyndham Hulme. Littlehampton.

THE present Patent Office search, extending back for fifty years for novelty, is, as Mr. Hulme says (NATURE, September 5, p. 356), really useless, and a fuller search ridiculous. To the inventor it is irritating: and it is of little value to the manufacturer, for before he gives a high price for the monopoly or spends much in adapting his plant and designs for using it, he, as a prudent man, will want something more.

Of course the granting of letters patent for overlapping existing protected inventions should be avoided, but that is all that is required. It should be open to any one to use the invention, or part of it, if he can show that it, or the part of it he is using, is old in the sense that it has actually been used; and a patent should not be invalidated because it, or part of it, has been described or figured a long time ago and forgotten until rediscovered by much "fever of the brow" and expenditure of time of the searchers.

Travers J. Briant.

The Old Cottage,

Wick, Littlehampton, Sussex.

\section{Analysis of the Arc Spectrum of Copper.}

STARTING from the constant frequency differences in the copper arc-spectrum, suggested by Rydberg, I have recently been able to deduce the values of a large number of new terms of that spectrum. My paper in the Philosophical Magazine (vol. 69, p. 951) has shown that copper gives a spectrum which is far from simple, and the further data now obtained show even greater complexity.

The new terms can be divided into two sets, those of the first set all being positive and combining with one or both of the known abnormally high $d$-terms. This set contains several terms already used in my paper. The inner quantum numbers are of course definite except in those cases where combinations with both $d_{2}$ and $d_{3}$ occur. The second set of terms consists altogether of negative terms which each combine with three or more of the first positive set, giving lines the wave-numbers of which differ from the calculated by not more than two-tenths of a wavenumber. Altogether, about 125 lines are accounted for by these new terms. The inner quantum numbers of the negative terms can be deduced, though with some uncertainty, from their combinations with the positive terms. The values of the terms are as follows, the probable nature and inner quantum numbers being given with each :

$5026 \cdot 2(j=4)$
$5656 \cdot 7(2$ or 3$)$
$6278 \cdot 2(4)$
$15709 \cdot 8(2$ or 3$)$
$17345 \cdot 2(4)$
$17763 \cdot 9\left(p_{2}\right)$
$17901 \cdot 8\left(d^{\prime}{ }_{3}\right)$
$18581 \cdot 9\left(d^{\prime}{ }_{2}\right)$
$18794 \cdot 1(4)$
$20005 \cdot 5\left(s^{\prime}{ }_{1}\right)$
$20745 \cdot 2(2)$
$21154 \cdot 7(4)$
$21364 \cdot 3\left(p_{1}\right)$
$22194 \cdot 0\left(p_{2}\right)$
$23289 \cdot 4(4)$

$$
\begin{aligned}
& -95 \cdot 2(3) \\
& -640 \cdot 2\left(p^{\prime}{ }_{3}\right) \\
& -1276 \cdot 4\left(p^{\prime}{ }_{1}\right) \\
& -8690 \cdot 0(3) \\
& -8819 \cdot 7(3) \\
& -8870 \cdot 1(3) \\
& -8960 \cdot 1(3) \\
& -9619 \cdot 1\left(p^{\prime}{ }_{2}\right) \\
& -9708 \cdot 6(3) \\
& -9758 \cdot 9\left(p^{\prime}{ }_{3}\right) \\
& -9785 \cdot 0(3) \\
& -10890 \cdot 7\left(p^{\prime}{ }^{2}\right) \\
& -10996 \cdot 5\left(p^{\prime}{ }_{2}\right) \\
& -14722 \cdot 0(5) \\
& -14760 \cdot 1(5)
\end{aligned}
$$

As yet I have been unable definitely to arrange many of these terms together either as doublets or quartets. It is evident, however, that quartets are involved. The difficulty arises partly from the large separations which are common in the copper spectrum and make estimations of relative intensities of lines of a multiplet uncertain. The complete analysis should afford tests of the theory of negative terms suggested by Russell and Saunders in their recent paper on the calcium spectrum.

Dr. L. A. Turner, of Harvard University, has recently suggested to me a possible explanation of the abnormally large inverted $d$-terms in the copper spectrum 5 II05.5 $\left(d_{3}\right)$ and $49062.6\left(d_{2}\right)$, based on considerations brought out in a paper by Pauli (Zeit. für Phys. 3I, IO). If we consider these terms as being due to the displacement of an electron from a $3_{32}$ or a $3_{33}$ group to the $4_{11}$ group, which is then closed, the atom might be considered as in a $d$-state. The inversion would be accounted for since the $3_{33}$ position is of higher energy than the $3_{32}$ position. Moreover, the formula $\Delta \nu / \mathrm{R}=(z-s)^{4} / 2 a^{2} / 3^{4}$ (Sommerfeld, p. 449) should yield a screening constant $s$ approximately equal to 13.0 , which is the value given by the separation of $\mathrm{M}_{32}$ and $M_{33}$ for atoms of high atomic number. The value found is $s=13 \cdot 6$, which is suggestively close, considering the large extrapolation, and the approximation involved in considering the two electrons in the $4_{11}$ ring as having the same effect in the two cases.

\section{Department of Physics, Toronto University, August 3 .}

\section{A. G. Shenstone.}

\section{Dispersal of Butterfies and other Insects.}

In the issue of Nature for September 5, Mr. E. P. Felt in his interesting article on the "Dispersal of Butterflies and other Insects" says, "It is quite possible that some insect movements are direct responses to a migration impulse." As bearing on this point, the following incident, which occurred some years ago, may not be without interest.

I was walking through a field of standing wheat that was growing on the Downs near Walmer, Kent; the sun was just below the horizon, the air warm and still, when I noticed that moths were rising from the wheat and flying vertically upwards until they were lost to sight. On closer inspection, I found that vast numbers of the silver $Y$ moth (Plusia gamma) were buzzing about among the wheat stems and that individuals were continually leaving their fellows and taking the upward flight. Although the larva of $P$. gamma will feed upon a great variety of lowgrowing plants, such as nettles, docks, and so forth, it is most unlikely that such numbers could have found sustenance on the weeds that might be growing in a fairly well kept wheat field, and the inference is that the moths had assembled among the wheat stems with the purpose of migration, and by their upward flight were seeking a favourable wind current to assist them in their journeyings in the upper air.

The incident, moreover, is not an isolated one, for Richard South describes a similar happening (Entomologist, I880, p. 42) which he had witnessed in the Isle of Wight: the insects were, he believes, the same species, but in his case they were rising from furze bushes.

“ Hodeslea," Meads,

Robert Adkin.

No. 29 I 7 , vOL. I I 6] 